\title{
Acoustic correlates of nasopharyngeal resonance
}

Marios Fourakis, Heather Karlsson, Christie Tilkens, Lawrence Shriberg

Waisman Center, University of Wisconsin-Madison, USA

https://doi.org/10.36505/ExLing-2010/03/0011/000131

\begin{abstract}
Measurements of F1 and F2 were made for the four corner vowels produced by typically-developing adolescents and adolescents with Fragile $\mathrm{X}$ and Down syndromes. The two high vowels were produced with lower F2 frequencies by the Fragile $\mathrm{X}$ and Down syndrome groups than the group of typically developing persons. This is consistent with a hypothesized backing of the tongue.
\end{abstract}

Key words: F1, F2, corner vowels, Fragile X, Down syndrome

\section{Introduction}

Primary goals of the Phonology Project are to identify etiologic origins, risk and protective factors, and diagnostic markers of eight subtypes of speech sound disorders of currently unknown origin (Shriberg, 2010).

The diagnostic instrument used in all Phonology Project studies is termed the Speech Disorders Classification System (SDCS: Shriberg et al., in submission). Perceptual methods to code participants' prosody and voice are based on extensions to the system described in The Prosody-Voice Screening Profiles (PVSP: Shriberg et al, 1992).

\section{Nasopharyngeal resonance}

The PVSP describes PV32: Nasopharyngeal Resonance as a "muffled," "back of the throat" quality consistent with the percept of "sluggish or imprecise tongue movement" sometimes used to characterize the speech of persons with Down syndrome. Several of the audio exemplars for PV32 in the PVSP manual were obtained from speakers with Down syndrome. As indicated in Kent and Read (2002) and others, if this "back of the throat" impression is a consequence of moving the tongue further back in the mouth than appropriate for a given vowel, the acoustic effect should be a lowering of F2.

\section{Method}

To test the sensitivity of F2 lowering as a potential acoustic correlate of perceived nasopharyngeal resonance, formant measurements of the

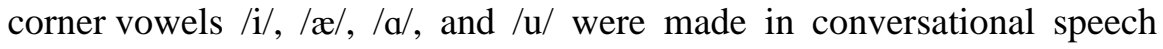
samples obtained from three databases in the Phonology Project audio archives: eight 15-to 19-year-old male speakers with Fragile $\mathrm{X}$ syndrome, eight 15-to17-year- old speakers with Down syndrome, and 5 typically-

ExLing 2010: Proceedings of 3rd Tutorial and Research Workshop on Experimental Linguistics, 25-27 August, Athens, Greece 
developing 14-year-old and 5 typically-developing 16-year-old male speakers. All tokens from each speaker came from one of their 24 CS utterances eligible for PVSP coding (i.e., were not excluded by one or more of the 32 PVSP exclusion codes). For the speakers with Fragile X syndrome, 3-12 of the 24 utterances had been coded PV32. For the speakers with Down syndrome, at least 22 of their 24 utterances had been coded PV32: Nasopharyngeal. None of the utterances from the 10 reference participants had been coded PV32.

F1 and F2 frequencies for all vowels in utterances coded PV32 were measured using the same procedures as described in the first section of this paper reporting an acoustic correlate for the percept of nasal resonance. The LPC used a number of coefficients appropriate to the sampling rate (SR+/- 4) for each person's recording, which ranged from 20 to $44.1 \mathrm{kHz}$, depending on the speaker group and the recording date.

\section{Results}

Figure 1 is a display of the means of $\mathrm{F} 1$ and $\mathrm{F} 2$ frequencies of the vowels produced by the speakers with Fragile $\mathrm{X}$ syndrome (triangle symbols) and the typically developing children (square symbols). In comparison to the values of the reference group, Fragile $\mathrm{X}$ speakers' lower F2 values for high vowels $/ \mathrm{i} /$ and $/ \mathrm{u} /$ is consisted with backing of the tongue. Effect sizes for these between-group differences are 1.18 (90\% CI $=0.25-1.99)$ for $/ \mathrm{i} /$ and $1.05(90 \% \mathrm{CI}=0.10-1.89)$ for $/ \mathrm{u} /$. Mean F1-F2 values for the low vowel /æ/ are generally similar for both groups. F1 and $\mathrm{F} 2$ values for the low vowel /a/ are higher for Fragile $\mathrm{X}$ speakers (effect size for $\mathrm{F} 2=2.17 ; 90 \% \mathrm{CI}=1.10-3.03$ ).

Figure 2 includes similar comparative findings for the speakers with Down syndrome and the typically-developing speakers. The betweengroup differences in vowel space are similar to those shown in Figure 1 for speakers with Fragile $\mathrm{X}$ syndrome. In comparison to values for the typical speakers, the high vowels for speakers with Down syndrome have lower F2 values, the vowel /e/ has higher F1 and F2 values, and the two speaker groups have similar values for the low vowel /æ/. The between-group F2 effect size for $/ \mathrm{i} /$ is $1.23(90 \% \mathrm{CI}=0.32-2.01)$ and for $/ \mathrm{u} /$ is $1.15(90 \% \mathrm{CI}=0.26-1.93)$. The between-group $\mathrm{F} 2$ effect size for $/ \mathrm{a} /$ is $1.06(90 \% \mathrm{CI}=0.18-1.84)$. 


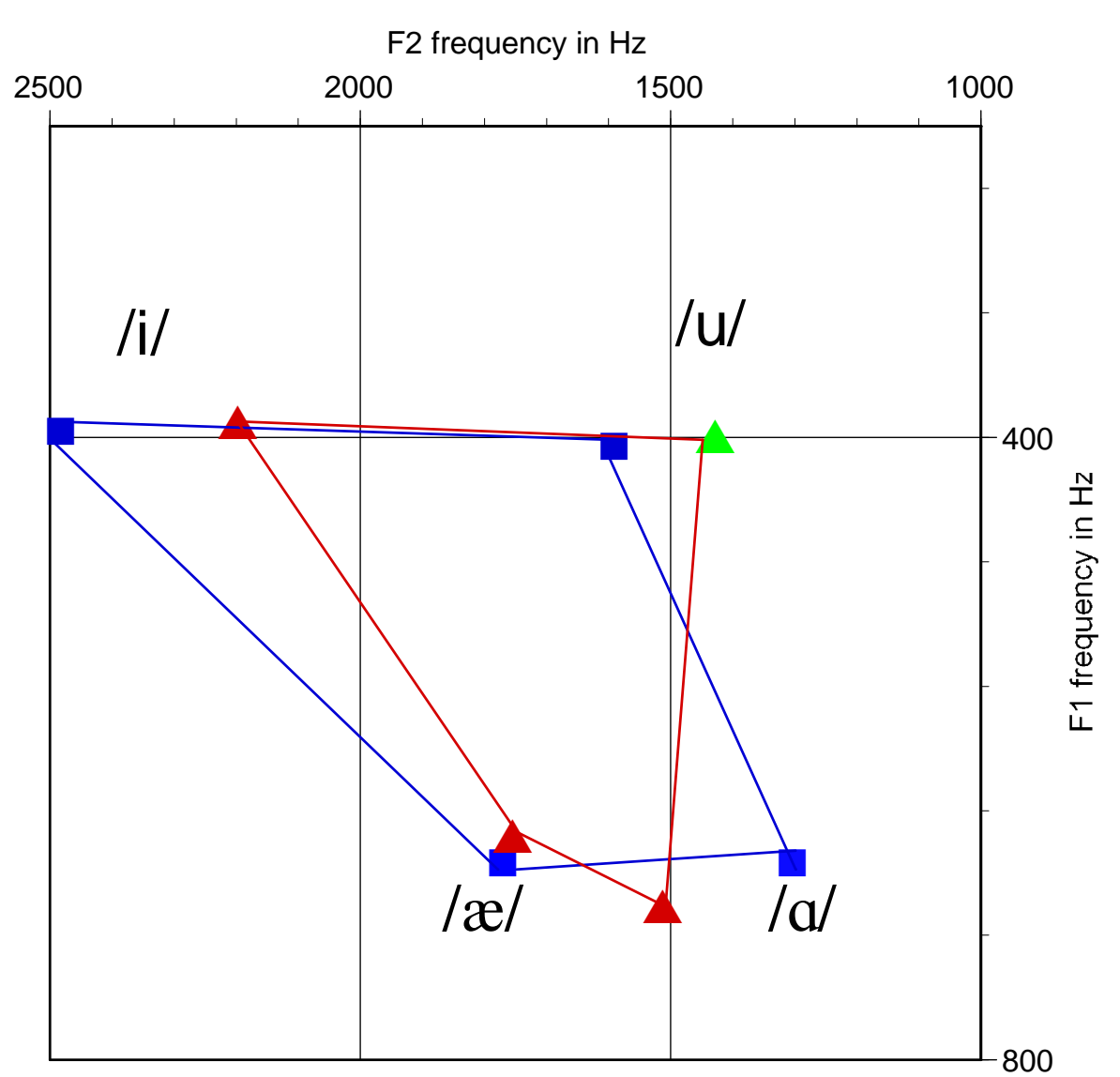

Figure 1. Mean F1 and F2 frequencies of corner vowels produced by adolescents with Fragile $\mathrm{X}$ syndrome (triangles) and typically-developing adolescents (squares).

\section{Conclusion}

The acoustic findings in Figures 1 and 2 are interpreted as support for lowered F2 values on high vowels as a reliable acoustic correlate of the percept of nasopharyngeal resonance. In both speaker groups with complex neurodevelopmental disorders, the percept of nasopharyngeal resonance was associated with F2 values further back in the vowel space than the corresponding vowels of typically-developing adolescents. Large, statistically significant effect sizes were obtained for both between-group comparisons. The acoustic findings emerging for all perceptual constructs in this research series, studies in progress will attempt to cross validate the present acoustic signature findings for nasal and nasopharyngeal resonance. 


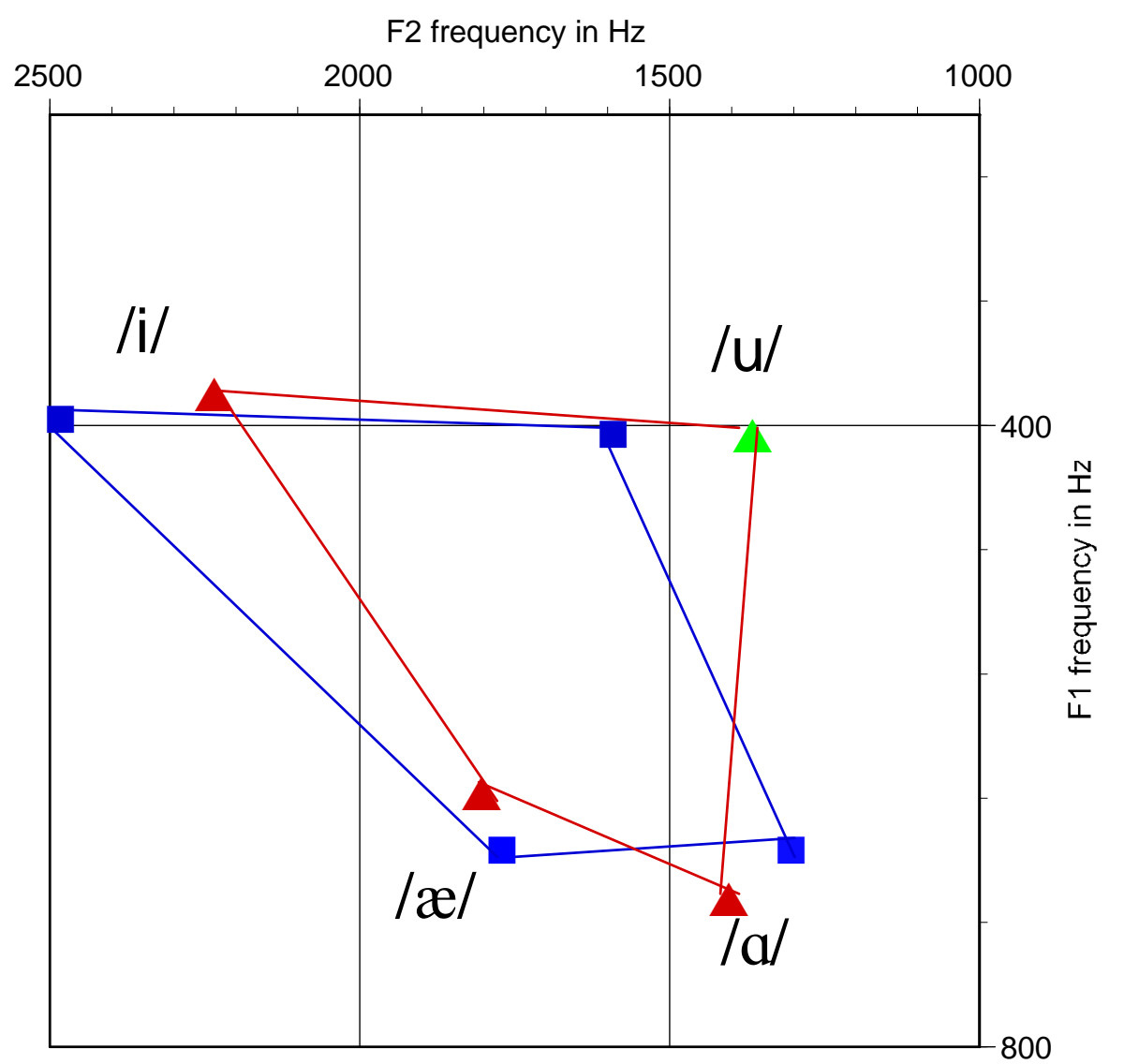

Figure 2. Mean F1 and F2 frequencies of corner vowels produced by adolescents with Down syndrome (triangles) and by typically-developing adolescents (squares).

\section{References}

Shriberg, L. 2010. Childhood speech sound disorders: From post-behaviorism to the post-genomic era. In Paul, R., Flipsen, P. (eds.), Speech Sound Disorders in Children. (pp. 1-34). San diego, CA: Plural Publishing.

Shriberg, L.D., Kwiatkowski, J., Rasmussen, C., Lof, G.L., Miller, J.F. 1992. The Prosody-Voice Screening Profile (PVSP): Psychometric data and reference information for children (Tech. Rep. No. 1). Phonology Project, Waisman Center, University of Wisconsin-Madison. 